\title{
Neurotoxicity of Tumor Immunotherapy: The Emergence of Clinical Attention
}

\author{
Benxia Zhang $\mathbb{D}^{1,2}$ Xue Li, ${ }^{1,2}$ Tao Yin, ${ }^{1,2}$ Diyuan Qin, ${ }^{1,2}$ Yue Chen, ${ }^{1,2}$ Qizhi Ma, ${ }^{1,2}$ Pei Shu, ${ }^{1,2}$ \\ and Yongsheng Wang $\mathbb{1}^{1,2}$ \\ ${ }^{1}$ Clinical Trial Center, \\ National Medical Products Administration Key Laboratory for Clinical Research and Evaluation of Innovative Drugs, \\ West China Hospital, Sichuan University, Chengdu, Sichuan, China \\ ${ }^{2}$ Department of Thoracic Oncology, State Key Laboratory of Biotherapy and Cancer Center, West China Hospital, \\ Sichuan University, Chengdu, Sichuan, China \\ Correspondence should be addressed to Yongsheng Wang; wangys@scu.edu.cn
}

Received 18 August 2021; Revised 10 December 2021; Accepted 15 December 2021; Published 18 January 2022

Academic Editor: Claudia Marchetti

Copyright (C) 2022 Benxia Zhang et al. This is an open access article distributed under the Creative Commons Attribution License, which permits unrestricted use, distribution, and reproduction in any medium, provided the original work is properly cited.

Tumor immunotherapy brings substantial and long-term clinical benefits that can even cure tumors. However, the accumulation of evidence suggests that immunotherapy also induces severe and complex neurologic immune-related adverse events (ir-AEs) and even leads to immunotherapy-related death, which arouses the concern of clinicians. The timely and accurate identification of neurotoxicity helps clinicians detect and treat these complications early, thereby enhancing treatment efficiency and improving the prognosis of patients. At present, the mechanism of neurotoxicity caused by immunotherapy has not been completely elucidated. This paper mainly reviews the clinical features, pathogenesis, and therapeutic strategies of neurologic ir-AEs.

\section{Introduction}

Tumor immunotherapy refers to novel therapeutic measures that turn the immune system into a destructive force against tumors [1]. In general, tumor immunotherapy involves immune checkpoint inhibitors, immunostimulating antibodies, cytokine therapy, therapeutic cancer vaccines, adoptive cellular therapy, oncolytic immunotherapy, etc. [2]. In recent years, tumor immunotherapy has achieved significant success in various cancers and has been one of the hotspots in the life sciences, especially immune checkpoint inhibitors and adoptive cellular therapy [3]. Immune checkpoint inhibitors (ICIs) are antibodies that target crucial signaling pathways, such as programmed death 1 (PD-1)/ programmed death-ligand 1 (PD-L1), and cytotoxic T-lymphocyte-associated protein 4 (CTLA-4), to improve the activation of T cells and enhance the immune response to cancer cells. Pembrolizumab (Keytruda), a humanized monoclonal anti-PD-1 antibody, is the first anti-PD-1 antibody approved by the FDA for the treatment of patients with unresectable or metastatic melanoma, non-small-cell lung cancer (NSCLC), head and neck squamous cell carcinoma, cervical cancer, colorectal cancer, and gastric/gastroesophageal junction cancer [4-10]. Adoptive cellular therapy transmits the sensitized T cells to patients with low cellular immune function, which helps patients obtain antitumor immunity. Adoptive cellular therapy, especially chimeric antigen receptor (CAR) T cell therapy, has gained unprecedented success among hematologic tumors [11]. Kymriah is the first CAR-T therapy based on CD19 approved by the FDA in 2017 [12]. Related studies have reported that the complete response rate of CD19-CAR-T cells in hematological malignancies is approximately $88-90 \%$ $[13,14]$.

Life sciences professionals believe that immunotherapy will revolutionize cancer treatment. Nevertheless, side effects caused by immunotherapy should not be underestimated, such as skin damage, ir-AEs, bone marrow depression, tumor lysis syndrome, coagulation disorders, etc. [15-18]. Recently, with the widespread use of immunotherapy, 
neurologic ir-AEs, such as encephalopathy, meningitis, neuropathy, and seizures, have aroused the concern of clinicians. It is a dose-limited factor of cancer immunotherapy and affects the prognosis and quality of life [15]. The incidence of the neurologic ir-AEs has varied in different immunotherapeutic agents. Blinatumomab is a bispecific T-cell engager (BiTE) targeting CD19 on malignant B cells and $\mathrm{CD} 3$ on normal host $\mathrm{T}$ cells. In a multicenter, singlearm, open-label phase 2 study on patients with relapsed or refractory B-precursor acute lymphoblastic leukemia, the distribution of any grade neurologic ir-AEs frequency was $52 \%$ among patients receiving blinatumomab, and grade 3 or 4 neurologic ir-AEs occurred in $11 \%$ and $2 \%$ patients, respectively [19]. The incidence rate for any grade ICIs-related neurologic ir-AEs in patients included in clinical trials has been reported to be approximately $3.8 \%$ to $12 \%$ [20]. The distribution of grade 3-4 neurologic ir-AEs frequency was $0.7 \%$ among patients receiving anti-CTLA-4 (ipilimumab and tremelimumab), $0.4 \%$ among patients receiving antiPD1 (nivolumab, pembrolizumab, lambrolizumab, and pidilizumab), and $0.7 \%$ among patients receiving a combination therapy (anti-CTLA-4 + anti-PD1) [20]. Any grade CAR-T-related neurologic ir-AEs, by contrast, have the highest incidence. $62.3 \%$ of patients experienced any grade neurologic ir-AEs [21]. Notably, in the JCAR015 Phase 2 Clinical Trial (ROCKET) conducted by Juno Therapeutics, five patients died because of severe cerebral edema, causing the cessation of clinical trials by the FDA [22]. Emphasizing the importance of recognizing the neurologic ir-AEs related to immunotherapy early, especially CAR-T therapy, can help clinicians differentiate treatment-related adverse effects from the progression of cancer within the nervous system and how intervening sooner leads to better outcomes. In this review, we shed new light on the clinical characteristics and possible mechanisms of neurologic ir-AEs and highlight their clinical management.

\section{Neurotoxic Features of Immunotherapy}

Neurologic ir-AEs are typically characterized by toxic encephalopathy manifesting as headache, delirium, confusion, dysphasia, impaired fine motor skills, somnolence, etc. [23]. Moreover, rare complications, such as Guillain-Barre syndrome (GBS) [24-27], myasthenia gravis (MG) [28, 29], cerebellar dysfunction, and aseptic meningitis have also been reported by several clinical cases. Most of these adverse effects are grade 1 or 2 , but in the clinical treatment process, $\geq$ grade 3 neurologic ir-AEs also occur in patients (the severity of ir-AEs is graded based on the Common Terminology Criteria for Adverse Events version 5.0 [30]). Clinicians need to master the neurologic ir-AEs characteristics. Here, we summarize the performance of neurologic ir-AEs, hoping to help clinicians make a rapid diagnosis.

2.1. Headache. Headache is one of the most common unspecific manifestations of neurologic ir-AEs associated with immunotherapy. Patients with a history of headache before treatment may be more susceptible to headache following treatment [31-34]. Patients may suffer from headaches during or shortly after the first infusion of cetuximab [33, 35], bevacizumab [36], ipilimumab [32], rituximab [37], chimeric antigen receptor T cells (CAR-T) [21], and pembrolizumab [38] (Table 1). The symptoms are mostly selflimited, persisting for several days and decreasing soon after finishing the treatment $[18,39]$. In addition, a headache might also be a manifestation of other complications, such as aseptic meningitis and acute encephalopathy.

2.2. Seizures. Seizures occur because of acute, recurrent, paroxysmal brain disorders caused by the excessive firing of brain neurons, and they may be related to immune system activation with a significant accumulation of inflammatory cytokines [40-42]. Rituximab, an anti-CD20 chimeric monoclonal antibody, is generally well tolerated in patients with relapsed or refractory non-Hodgkin's lymphoma [43]. However, rituximab-induced seizures were occasionally reported and usually appeared within hours after injection of rituximab [44]. Seizures are the most common presenting symptom of posterior reversible encephalopathy syndrome (PRES) induced by rituximab [44-47]. PRES is thought to be associated with the failure of the autoregulation of cerebral blood pressure and local central nervous system inflammation. Once the patients develop seizures, rituximab infusion should be interrupted [48]. Other immunotherapeutic agents, such as bevacizumab, ipilimumab, and sunitinib, may also induce PRES in less than $1 \%$ of the treated patients [49-51]. In addition, blinatumomab causes seizures in $3 \%$ to $4.8 \%$ of the treated patients in clinical studies, and the seizures begin within the first two days of infusion [34, 52]. Zimmer, L. and colleagues have found that $0.4 \%$ of patients receiving pembrolizumab or nivolumab developed seizures in a retrospective study of 496 patients with melanoma. Additionally, seizures occur upward in 3\% of patients after CD19-CAR T cells infusion and are related to the dose of CAR-T cells. Seventy-two percent of patients with severe neurologic ir-AEs during CAR-T treatment might develop generalized tonic-clonic seizures [21]. Patients who suffered from seizures during the treatment can be evaluated with head computed tomography (CT), magnetic resonance imaging (MRI), electroencephalograms (EEGs), and lumbar punctures. In general, the EEG findings were frontal intermittent rhythmic delta activity (FIRDA) and a diffused or frontal slowing wave [21]. The analysis of cerebrospinal fluid (CSF) collected by lumbar puncture may indicate lymphocytosis [13]. CT and MRI were used to exclude differential diagnoses, such as tumor metastasis. Seizures usually improved with drug withdrawal, but steroids may be required to reverse in some circumstances $[18,53]$.

2.3. Encephalopathy. Acute encephalopathy is characterized by acute alteration of mental status, which is a common immunotherapy-related neurotoxic symptom $[21,54,55]$. Clinical features included confusion, delirium, cognitive impairment, speech disorders, impaired attention, and dizziness [55, 56]. Immunotherapeutic 
TABLE 1: Clinical features of immunotherapy-induced neurologic ir-AEs.

\begin{tabular}{|c|c|c|c|c|}
\hline & Agents & Clinical features & Diagnostic assessments & Treatments \\
\hline Headache & $\begin{array}{c}\text { Cetuximab; rituximab } \\
\text { (rituxan); lucatumumab; } \\
\text { ipilimumab; } \\
\text { pembrolizumab; } \\
\text { tremelimumab }\end{array}$ & Unspecific & $\begin{array}{l}\text { The status of patients } \\
\text { should be monitored } \\
\text { closely }\end{array}$ & Mostly self-limited \\
\hline $\begin{array}{l}\text { Acute } \\
\text { encephalopathy }\end{array}$ & $\begin{array}{c}\text { Rituximab; ipilimumab; } \\
\text { bevacizumab; alemtuzumab; } \\
\text { tremelimumab; } \\
\text { pembrolizumab; } \\
\text { blinatumomab; CD19-CAR- } \\
\text { T }\end{array}$ & $\begin{array}{l}\text { Confusion, delirium, } \\
\text { cognitive impairment, } \\
\text { speech disorders, } \\
\text { impaired attention, } \\
\text { and dizziness }\end{array}$ & $\begin{array}{l}\text { MRI, CT, EEG, and lumbar } \\
\text { punctures }\end{array}$ & $\begin{array}{l}\text { Drug pausing or withdrawal; } \\
\text { steroids }\end{array}$ \\
\hline $\begin{array}{l}\text { Chronic } \\
\text { encephalopathy }\end{array}$ & $\begin{array}{c}\text { Rituximab; brentuximab; } \\
\text { nivolumab; alemtuzumab; } \\
\text { CAR-T therapy }\end{array}$ & $\begin{array}{l}\text { Progressive dementia, } \\
\text { cognitive dysfunction, } \\
\text { personality change, } \\
\text { blunted effect, and } \\
\text { amnestic syndrome }\end{array}$ & $\begin{array}{l}\text { Neuropsychological testing, } \\
\text { lumbar puncture, MRI, } \\
\text { EEG, and laboratory } \\
\text { assessments }\end{array}$ & $\begin{array}{l}\text { Discontinuation of the treatment, } \\
\text { plasmapheresis, and steroids. }\end{array}$ \\
\hline PRES & $\begin{array}{l}\text { Rituximab; blinatumomab; } \\
\text { CD19-CAR-T; } \\
\text { bevacizumab; ipilimumab; } \\
\text { sunitinib }\end{array}$ & $\begin{array}{l}\text { Seizures, headache, } \\
\text { confusion, visual } \\
\text { changes }\end{array}$ & $\begin{array}{c}\text { MRI, CT, lumbar } \\
\text { punctures, EEG, and blood } \\
\text { pressure assessment }\end{array}$ & $\begin{array}{l}\text { Discontinue immunotherapy, } \\
\text { prevent ischemia, steroids, and } \\
\text { antiepileptic drugs }\end{array}$ \\
\hline $\begin{array}{l}\text { Aseptic } \\
\text { meningitis }\end{array}$ & $\begin{array}{c}\text { Cetuximab; pembrolizumab; } \\
\text { nivolumab; ipilimumab; } \\
\text { CD19-CAR-T }\end{array}$ & $\begin{array}{l}\text { Unspecific headaches, } \\
\text { photophobia, neck } \\
\text { stiffness, and altered } \\
\text { mental status }\end{array}$ & $\begin{array}{l}\text { Lumbar punctures, CT, } \\
\text { MRI bacterial culture, viral } \\
\text { culture, and fungal culture }\end{array}$ & $\begin{array}{l}\text { Generally self-limited. Drug } \\
\text { withdrawal, intravenous high- } \\
\text { dose methylprednisolone, } \\
\text { dexchlorpheniramine, or } \\
\text { equivalent metered } \\
\text { dexamethasone }\end{array}$ \\
\hline $\begin{array}{l}\text { Peripheral } \\
\text { neuropathy }\end{array}$ & $\begin{array}{c}\text { Rituximab; ofatumumab; } \\
\text { dacetuzumab; brentuximab } \\
\text { vedotin; gemtuzumab } \\
\text { ozogamicin; ipilimumab; } \\
\text { pembrolizumab; nivolumab; } \\
\text { blinatumomab; provenge } \\
\text { vaccine }\end{array}$ & $\begin{array}{l}\text { Sensory deficits, motor } \\
\text { deficits }\end{array}$ & $\begin{array}{c}\text { CT, MRI, lumbar } \\
\text { punctures, } \\
\text { electrophysiological } \\
\text { assessment, and clinical } \\
\text { assessment }\end{array}$ & $\begin{array}{c}\text { Drug withdrawal and } \\
\text { glucocorticoid; severe peripheral } \\
\text { neuropathy: methylprednisolone } \\
7.5-30 \mathrm{mg} / \mathrm{kg} / \text { day plus tacrolimus } \\
0.15 \mathrm{mg} / \mathrm{kg} \text { twice a day, } \\
\text { plasmapheresis }\end{array}$ \\
\hline $\begin{array}{l}\text { Cerebellar } \\
\text { dysfunction }\end{array}$ & $\begin{array}{l}\text { Ofatumumab; trastuzumab; } \\
\text { ipilimumab; blinatumomab }\end{array}$ & $\begin{array}{l}\text { Ataxia, nystagmus, } \\
\text { confusion, scanning } \\
\text { speech, and confusion }\end{array}$ & MRI, CT, EEG & Drug withdrawal and steroids \\
\hline MG & $\begin{array}{l}\text { Ipilimumab; } \\
\text { pembrolizumab }\end{array}$ & $\begin{array}{l}\text { Fatigable weakness in } \\
\text { proximal limb muscles, } \\
\text { ptosis, dyspnea, and } \\
\text { diplopia }\end{array}$ & $\begin{array}{c}\text { Blood test for AChR } \\
\text { antibodies and MUSK, } \\
\text { electromyography, CT, and } \\
\text { MRI }\end{array}$ & $\begin{array}{l}\text { Discontinuation or withholding of } \\
\text { drugs was recommended; } \\
\text { corticosteroids and } \\
\text { immunoglobulin }\end{array}$ \\
\hline GBS & ICIs; TCR-T therapy & $\begin{array}{l}\text { Progressive ascending } \\
\text { symmetry paralysis, } \\
\text { proximal limb } \\
\text { weakness, and } \\
\text { peripheral sensory } \\
\text { disturbance }\end{array}$ & $\begin{array}{l}\text { Clinical features, MRI, } \\
\text { electromyography, nerve } \\
\text { conduction studies, and } \\
\text { lumbar puncture }\end{array}$ & $\begin{array}{c}\text { Discontinue immunotherapy, } \\
\text { corticosteroids therapy } \\
\text { combination with IVIG or } \\
\text { plasmapheresis }\end{array}$ \\
\hline
\end{tabular}

PRES: posterior reversible encephalopathy syndrome; GBS: Guillain-Barre syndrome; MG: myasthenia gravis; ICIs: immune checkpoints inhibitors.

agents, such as ipilimumab, blinatumomab, bevacizumab, and CAR-T cells therapy, might induce acute alteration of mental status in treated patients $[13,50,55,57,58]$. In a study of adult patients with relapsed or refractory CD19 $B$ acute lymphoblastic leukemia, grade $\geq 3$ neurotoxicity occurred in $50 \%$ of patients either concurrent with or after cytokine release syndrome (CRS), and most of them manifested as mild-to-severe encephalopathy, focal neurologic deficits, and seizures [59]. Although the pathogenesis of CAR-T cell therapy-induced encephalopathy remains inadequately understood, it is believed that endothelial activation, capillary leakage, disseminated intravascular coagulation, and increased bloodbrain barrier (BBB) permeability are related to CAR-T cell induced neurotoxicity [42]. Similar T cell-mediated endothelial activation and the disruption of $\mathrm{BBB}$ are observed with blinatumomab [41]. CT, MRI, and lumbar punctures can be performed to exclude brain metastasis. In recent years, studies have discovered that serum IL-6, IL-8, IL-10, IL-15, CCL2, TGF- $\beta$, TNF- $\alpha$, C-reactive protein (CRP), and IFN- $\gamma$ concentrations early after CART cell infusion may be helpful to identify whether patients 
are at risk of developing life-threatening toxicity $[59,60]$. Blinatumomab and CAR-T therapy-related encephalopathy are primarily reversible and can be resolved several days without intervention or by discontinuation of the drugs $[13,42,52]$.

Chronic encephalopathy, such as leukoencephalopathy, could be induced by direct brain parenchyma damage. Chronic encephalopathy usually develops months after receiving cancer immunotherapy [50]. Clinical symptoms included progressive dementia, cognitive dysfunction, personality change, blunted effect, and amnestic syndrome. A specific cause of chronic mental state changes is progressive multifocal leukoencephalopathy (PML), a rare demyelinating disease induced by the activation of the latent John Cunningham (JC) virus. PML primarily occurs in individuals with severe immunosuppression, especially with HIV-1 infection [61]. Recently, PML has been increasingly diagnosed in patients receiving immunotherapeutic agents that modulate immune system functions, such as rituximab [62], brentuximab [63], nivolumab [64], alemtuzumab [65], and CAR-T therapy [66]. Related research has indicated that cancer immunotherapy-induced PML might rely on activating previously exhausted polyoma-specific $\mathrm{T}$ cells [64-66]. Diagnostic assessment should be comprehensive, which includes neuropsychological testing, lumbar puncture, MRI, and laboratory assessments. Brain atrophy and ventriculomegaly may be seen in MRI imaging for some patients with chronic encephalopathy $[63,65,66]$. Interventions include the discontinuation of treatment, plasmapheresis, and steroids.

2.4. Peripheral Neuropathy. Peripheral neuropathy includes peripheral sensory neuropathy and peripheral motor neuropathy. Peripheral neuropathy is a dose-limiting neurotological adverse effect secondary to tumor immunotherapy. Most of the peripheral neurological symptoms involve sensory nerves and are almost grade 1 or 2 [67]. Most peripheral neuropathies present with symmetric and "stocking- and glove-like" paresthesia. Brentuximab, an antibody against CD30 on the B and T cells, is used to treat an anaplastic large cell and refractory Hodgkin lymphoma. Peripheral neuropathy developed in $22 \%$ of patients receiving brentuximab and typically presented with grade 1 or 2 . The median time to the onset of peripheral neuropathy was nine weeks (range from 3 to 24 weeks) [68]. Brentuximab should be stopped once diagnosed with peripheral neuropathy until symptoms improve to grade 1 . After resolution, brentuximab could be reinitiated at a lower dose. Additionally, peripheral sensory neuropathy is also a prominent side effect of ipilimumab [55], nivolumab [69], pembrolizumab [70], and rituximab [48]. The possible mechanism is that the drugs disturb the normal axonal transport $[48,67,68,71-77]$. For patients with peripheral neuropathy, CT, biochemical tests, and MRI can be helpful for diagnosis. $\mathrm{CT}$ and MRI are used to exclude brain metastasis, while the biochemical examination of CSF may show only a protein increase [78]. Peripheral neuropathy is often self-limited and can be resolved by drug withdrawal.
2.5. Cerebellar Dysfunction. The main functions of the cerebellum are maintaining the balance of the human body and controlling the posture and gait. Cerebellar dysfunction presents with ataxia, nystagmus, confusion, scanning speech, and confusion. Cerebellar dysfunction is a rare complication of ipilimumab [79, 80], trastuzumab [81], and blinatumomab [53]. It is usually pronounced in elderly patients and patients with preexisting neurological conditions or renal dysfunction. Evidence shows that $2.1 \%$ of patients using blinatumomab may develop cerebellar dysfunction, and the symptoms are usually reversible with the discontinuation of the drug [82]. CT and MRI could be used to exclude brain metastasis, and EEG may be observed only as a slow wave.

2.6. Myasthenia Gravis (MG). MG, an autoimmune disease caused by the dysfunction of the neuromuscular junction, is a rare but life-threatening side effect related to tumor immunotherapy. MG usually involves the extraocular muscles at the beginning, followed by other muscle groups. The clinical symptoms include fatigable weakness in proximal limb muscles, ptosis, dyspnea, and diplopia [83]. In severe cases, patients involving respiratory muscle dysfunction may need breathing support. Immunotherapy-induced MG is an increasingly recognized and feared complication of ICIs [84, 85]. Although MG exacerbation has been reported in patients who have had stable myasthenia during ICIs therapy, ICIs-related MG appears to be primarily new with no previous clinical history of MG $[29,86]$. The average onset of MG-related symptoms was four weeks (from six days to 16 weeks) of ICIs. The median time from symptom onset to respiratory failure demanding intubation was seven days [83]. Almost all patients with ICIs-related MG need hospitalization, and $40-50 \%$ of them require mechanical ventilation [83, 87]. The elevation of acetylcholine receptor (AChR) antibodies was reported in laboratory tests in $66 \%$ of the tested patients [83]. For seronegative patients for AChR antibodies, $50 \%$ to $70 \%$ were seropositive for antibodies to muscle-specific kinase (MUSK). Electromyography could detect the features of MG in $41 \%$ of patients. CT and MRI were usually normal. The discontinuation or withholding of ICIs was recommended. According to the severity of the condition, intravenous methylprednisolone, intravenous immunoglobulin, or plasmapheresis can be used to improve symptoms [85, 88]. A few cases of $M G$ have also been reported in studies combining anti-PD-1/PD-L1 monoclonal antibody with anti-CTLA-4 monoclonal antibody [89], but which one induced MG remains to be confirmed. We found that most patients with MG are women. Whether this is a coincidence or drug-induced MG affects females remains to be clarified.

2.7. Guillain-Barre Syndrome (GBS). GBS is an autoimmune peripheral neuropathy characterized by the demyelination of peripheral nerves and nerve roots, infiltration of small vascular inflammatory cells, and acute inflammatory demyelinating polyneuropathy (AIDP) [90]. Episodes are triggered mainly by an infectious process. Clinical manifestations 
include progressive ascending symmetry paralysis, proximal limb weakness, and peripheral sensory disturbance. ICIsrelated GBS is a rare neurologic ir-AE with an incidence of less than $1 \%[25,26]$, and it frequently presents as swiftly ascending paresthesia in the hands and feet over days within the first 3-4 ICIs cycles. Increased creatine kinase (CK) ranging from mild to high levels presents more frequently in ICIs-related MG than ICIs naive patients [91]. TCR-T cell therapy-induced GBS has also been increasingly recognized. The onset of GBS-related symptoms ranges from 19 days to 142 days of TCR-T therapy initiation and shows a rapidly progressive and bilateral ascending weakness [24, 92]. The diagnosis is mainly clinical, but may be facilitated by additional investigations, such as brain MRI, electromyography (EMG), nerve conduction studies, and lumbar puncture. MRI of the brain and the spinal cord can be used to exclude disease progression. EMG may show a diagnostic significance for generalized motor and sensory demyelinating polyneuropathy. Albuminocytologic dissociation is often noted in CSF, but it is worth noting that there have been cases of rapidly ascending weakness that lack classic albuminocytologic dissociation. Although high-dose corticosteroid therapy (40 mg methylprednisolone administered by intravascular injection twice per day) has been used to improve the symptoms in cases, corticosteroids are of little benefit in immunotherapy-induced GBS, and the current guidelines recommend consideration of corticosteroid therapy in combination with IVIG or plasmapheresis [25].

2.8. Aseptic Meningitis. Aseptic meningitis has been noted in several different immunotherapeutic agents, such as cetuximab [93], pembrolizumab, nivolumab [94], and ipilimumab [95]. Meningitis was more likely to present with additional non-neurologic immune-related adverse effects. Symptoms include unspecific headaches, photophobia, neck stiffness, and altered mental status. It is challenging to distinguish meningitis from encephalitis in patients with metastatic cancer or patients presenting with new seizures and cognitive impairment. Aseptic meningitis was probably related to markedly elevated inflammatory cytokines, such as IL-6, IL-2, interferon- $\gamma$, and tumor necrosis factor-alpha (TNF- $\alpha$ ). Patients who developed aseptic meningitis can be tested by lumbar punctures, CT, and contrast brain MRI. CSF findings typically demonstrate lymphocytes as the central part, normal-to-low glucose values, and elevate protein. MRI might show abnormal diffuse thickening of the dura mater. CT, bacterial culture, viral culture, and fungal culture are often negative. Steroids can be used to improve the symptoms. NCCN guidelines recommend patients who experience mild-to moderate-grade meningitis rechallenge treatments when there is complete symptom resolution [96].

Other symptoms, including transient vision loss, hypothalamic or pituitary gland disorder [97, 98], depression, dizziness [99, 100], acute inflammatory demyelinating polyneuropathy, and chronic inflammatory demyelinating polyneuropathy (CIDP), were also occasionally reported. According to the clinical symptoms, blood tests, biochemical tests, cerebrospinal fluid puncture, and head imaging can be used to make a precise diagnosis, followed by symptomatic supportive care.

2.9. Predictors and Assessment of Neurologic ir-AEs. At present, there are still no proven biomarkers to predict neurologic ir-AEs in patients undergoing the administration of ICIs. However, limited evidence has indicated that CART-related neurotoxicity is related to tumor burden, the number of CAR-T cells infused, previous lymphodepleting chemotherapy (fludarabine and cyclophosphamide), age, and previous chemotherapy. Neurologic ir-AEs can be defined and graded using the CTCAE or ASTCT ICANS grading system. Indeed, recent studies have proved that the CTCAE grading system overestimates the incidence of grade 1 or 2 neurological adverse events [101]. Guidelines for immune-related adverse effect management have been established by the American Society of Clinical Oncology (ASCO) and the National Comprehensive Cancer Network (NCCN).

2.10. Pathogenesis of Neurologic ir-AEs. Traditional chemotherapy- and radiotherapy-induced neurotoxicity has been widely recognized in patients with cancer. The central nervous system contains stem cells and slowly splitting glial cells that supply some neuronal populations. Chemotherapy preferentially acts on the dividing cells. The central nervous system is an unexpected target of agents that affect the dividing cells. Likewise, radiation therapy (RT) targets the dividing cells and can cause damage to the neural structures directly or indirectly by causing vascular damage, fibrosis of neural structures, and endocrine disturbance. Accordingly, depending on the region of the brain involved, RT can lead to stroke-like migraine, aphasia, hemiparesis, seizures, and so on.

Compared with traditional therapy, neurologic ir-AEs are more severe. Immunotherapeutic agents can activate the endothelial cells and damage the nerve system directly by upregulating the immune system to release cytokines. In some cases, these cytokines can cause brain edema, resulting in the death of patients $[16,102]$. Given the protection of $\mathrm{BBB}$ and the low proliferative rate of neurons, the nervous system should be well protected from the toxic effects of immunotherapy and traditional therapy. However, some immunotherapeutic agents can still concentrate in the cerebrospinal fluid to act on the normal brain tissue [103]. Additionally, preexisting neurologic comorbidities are correlated with an increased risk of neurologic ir-AEs. Moreover, cyclophosphamide and fludarabine lymphodepletion, a higher infused CAR-T cell dose, and a higher burden of malignant cells increased the risk of developing CAR-T therapy-related neurotoxicity [42].

2.11. Upregulation of the Immune System. Immunotherapeutic agents such as blinatumomab and CAR- $T$ cells can activate the $\mathrm{T}$ lymphocytes to release various cytokines into the blood and cause a group of symptoms. This process is called CRS [104, 105]. Although 
recent research shows that the neurologic ir-AEs are irrelevant to CRS, there is evidence that patients who undergo CRS after immunotherapy are more vulnerable to developing neurologic ir-AEs $[13,106]$. Studies have demonstrated that neurologic ir-AEs secondary to CAR-T therapy is probably related to the markedly elevated inflammatory cytokines, such as IL-6, IL-2, interferon- $\gamma$, and TNF- $\alpha$ $[16,102,107,108]$. Moreover, Norelli and colleagues proved that elevated IL-1 and IL-6 after CAR-T cell infusion are secreted by human monocytes [109]. In addition, aseptic meningitis is related to high levels of IL-6, IL-2, and interferon- $\gamma$ in meninges. Seizures, acute encephalopathy, and peripheral neuropathy secondary to immunotherapy are also associated with high levels of cytokines $[59,60,110,111]$. Importantly, immunotherapeutic agentsinduced high levels of cytokines in the cerebrospinal fluid can lead to cerebral edema [112], which can cause paralysis, motor aphasia, and even the death of patients. Mayhan, W. G. found that TNF- $\alpha$ can increase the permeability of BBB and some peripheral organ barriers, allowing the kinds of cytokines to enter the central nervous system [113]. Therefore, TNF- $\alpha$ might play an important role in the pathology of immunotherapy-induced neurotoxicity.

Moreover, Hua-bing Wang et al. demonstrated that antiCTLA- 4 antibody treatment provoked MG by enhancing the $\mathrm{T}$ cell responses to AChR and increasing anti-AChR Ab production in mice [28]. Nivolumab-induced MG has also been found to be associated with increased anti-AchR antibodies [85]. In addition, some immunotherapeutic agents can activate the immune system to produce more cytotoxic Tcells and subdue the regulatory T cells, leading to decreased peripheral tolerance to autoantigens, resulting in autoimmunity in different organs and causing symptoms such as GBS $[25,114,115]$.

2.12. Cross-Reactivity with Cells from Normal Tissue. Cross-reactivity between the cells from the nervous system and tumor cells contributes to developing immunotherapeutic neurological toxicity [103]. "On tumor off target" adverse effect is defined as some target drugs binding to antigens expressed in the brain tissue that are similar to the antigens expressed in tumors. It has been confirmed that the melanocytes and Schwann cells are derived from the same neural crest and share some similar antigens. Therefore, an immune response against the melanocyte antigens may also attack similar antigens on the Schwann cells. Wilgenhof, $S$. and colleagues demonstrated that ipilimumab-induced GBS is caused by an incorrect attack on the cell surface ganglioside-related epitopes expressed in the human peripheral nerve axolemma [25]. Immunotherapy-induced chronic encephalopathy and headache were also related to the "on tumor off target" effect [116]. However, it is regrettable that the "on tumor off target" effect is extremely difficult to predict from preclinical studies because of the difference in the antigenic repertoire between the animal models and humans.

Moreover, some specific antigens are expressed not only in the tumor but also in the normal tissue. Immunotherapy targeting these same antigens in the normal tissue may cause side effects. In a clinical trial, researchers found that CD19 was regionally or temporally expressed on the neurons or glial cells. Therefore, the infused CD19 CAR-T cells can attack these neurons or glial cells [117]. In addition, the inhibitors of VEGF can increase the risk of stroke, ischemia of the nerve, and temporal arteritis in patients by increasing the permeability of the blood vessels and inducing thrombosis in newly formed tumor-associated blood vessels and normal vessels [118]. These processes might lead to hemiplegia, numbness, transient vision loss, etc., in patients receiving anti-VEGF antibodies [119-121]. The previous studies of CD22 have confirmed that CD22 is highly expressed on aged microglia [122]. However, CD22-CAR-T therapy-related neurologic ir-AEs have not been reported to have a higher incidence.

2.13. Direct Injury. A few immunotherapeutic agents directly penetrate $\mathrm{BBB}$ and cause short-term or long-term injury to the central nervous system progenitor cells and nondividing oligodendrocytes. Gust, J. et al. have discovered that severe neurotoxicity is associated with disseminated intravascular coagulation (DIC), elevated prothrombin time, and higher peak concentrations of CRP, ferritin, and multiple cytokines, including IL6, IFN- $\gamma$, and TNF- $\alpha$, after CAR$\mathrm{T}$ cells infusion. Furthermore, they demonstrated that the pericytes secreted more IL6 and VEGF via IFN- $\gamma$ and TNF$\alpha$. Both IL6 and VEGF activate the endothelial cells and increase BBB permeability. In addition, IFN- $\gamma$ also downregulates PDGFR $\beta$ and upregulates the cleaved caspase- 3 expression, consistent with the induction of pericyte stress. The angiopoietin (ANG)-TIE2 axis, a pathway that regulates the endothelial cell quiescence and activation, has been described to be abnormally activated in patients with grade $\geq 4$ neurotoxicity compared to those with grade $\leq 3$ neurotoxicity. These findings indicated that increased BBB permeability allowed the high concentrations of cytokines such as IFN $\gamma$ and $\operatorname{TNF} \alpha$, to transit into CSF, which resulted in pericyte stress and secretion of cytokines that promoted a further increase of BBB permeability [42].

2.14. Others. In addition, scientists have found that the existing hyperferritinemia in patients with neurologic ir-AEs raises the probability that the activation of macrophagelineage cells may be associated with the pathogenesis of neurologic ir-AEs [123]. Autoimmune hypophysitis might cause hormonal deficiencies, which will lead to the changes of the neurotransmitter in the synaptic cleft [124]. It has also been reported that the activation of voltage-gated sodium channels can lead to axonal injury, and the gain-of-function mutations of the sodium channel may be linked to peripheral neuropathy [125].

2.15. Treatments. The exact mechanism of neurologic ir-AEs remains to be elucidated. Most data are obtained from anecdotal reports and case series. Generally, the management aims to prevent further clinical deterioration and avoid 
the manifestation of irreversible neurological deficits. Close monitoring, drug dose adjustment, or withdrawal might be effective for patients with grade 1 or 2 neurotoxic adverse effects [74, 106]. Immunotherapeutic agents should be discontinued in patients who develop grade $\geq 3$ neurotoxicity, and corticosteroids are generally used at most centers.

Immunotherapy-induced aseptic meningitis is generally self-limited. In severe cases, patients can be treated with intravenous high-dose methylprednisolone (about $80 \mathrm{mg}-160 \mathrm{mg}$ ), dexchlorpheniramine, or equivalent metered dexamethasone $[95,111,126]$. Dexchlorpheniramine $50 \mathrm{mg}$ can be applied before treatment to prevent the occurrence of aseptic meningitis [127]. For patients who develop seizures or GBS during the administration of immunotherapy, the therapeutic agents should be discontinued immediately, and glucocorticoids are needed for management as soon as possible $[26,128,129]$. High-dose glucocorticoids may be required if the symptoms further deteriorate $[25,130,131]$. Peripheral neuropathy induced by immunotherapy can also be treated with glucocorticoids. For severe peripheral neuropathy involving limb motor dysfunction, hormone shock therapy (methylprednisolone $7.5-30 \mathrm{mg} / \mathrm{kg} /$ day) can be used. If symptoms worsen, the addition of tacrolimus $0.15 \mathrm{mg} / \mathrm{kg}$ twice a day to hormone shock therapy significantly improved the prognosis of patients [78]. In addition, high-dose corticosteroids and hormone replacement are also supposed to be used for patients with therapy-induced hypophysitis [132-135]. An elaborative approach to the glucocorticoid taper and appropriate patient counseling is necessary to assure a successful taper after the neurological symptoms have abated.

Immunoglobulin is another commonly used drug. For patients with immunotherapy-induced MG or GMS, immunotherapeutic agents should be discontinued immediately, and intravenous immunoglobulin can relieve symptoms $[25,26]$. Patients who experience mild to moderate grade immunotherapy-induced neurologic ir-AEs can rechallenge treatments upon complete symptom resolution. However, if the immunotherapy-induced neurologic ir-AEs occur more than once, the agents should be permanently discontinued.

Sedative drugs and antiepileptic drugs have been proposed to address immunotherapy-induced seizures. In general, intravenous lorazepam or oral levetiracetam can be used to improve the symptoms of seizures $[26,128,129,131]$. Additionally, antidepressants can also be used to control peripheral neuropathy in some cases [136-138].

Anti-IL-6 receptor antibodies, such as tocilizumab can be used to treat CRS. Fortunately, tocilizumab mainly acts on monocytes and macrophages so that the efficacy of immunotherapeutic agents will not be significantly weakened [107, 117]. However, tocilizumab has no effect in most cases of neurologic ir-AEs. It may be because of the pathological differences between CRS and neurologic ir-AEs and poor penetration of tocilizumab across BBB. Recently, Norelli and colleagues have found that IL-1 receptor antagonists may be helpful for controlling the symptoms of CAR-T-related neurotoxicity.
In addition, plasmapheresis can also help improve the symptoms of peripheral neuropathy and drug-induced MG $[26,78]$. Moreover, other cytokine inhibitors, such as itacitinib and ibrutinib, have been shown to reduce CAR-T cellrelated toxicity in preclinical models $[139,140]$.

\section{Conclusion}

With the rapid development and widespread use of immunotherapy, its therapeutic effect has been widely recognized by clinicians. However, increasing attention has also been paid to immunotherapy-induced adverse effects simultaneously, especially neurotoxicity, because it is a limiting factor for accomplishing the course of treatment. Compared with traditional radiotherapy and chemotherapy, neurologic ir-AEs secondary to immunotherapy are more complex because of some new patterns of neurotoxic symptoms. We are now facing the following problems: firstly, the mechanisms of neurologic ir-AEs have not yet been elucidated. Secondly, there are still no specific diagnostic criteria for neurologic ir-AEs. Finally, there is no consensus on how to address these complications. Thus, a large number of studies concerning the questions mentioned above are supposed to be carried out. Meanwhile, the existing treatment strategies should be optimized to decrease the risk of nervous system damage and improve the survival of patients.

\section{Data Availability}

The data used to support the findings of this study are included within the article.

\section{Conflicts of Interest}

The authors declare that the research was conducted in the absence of any commercial or financial relationships.

\section{Authors' Contributions}

Zhang BX contributed significantly to analysis and manuscript preparation. Xue Li, Tao Yin, Diyuan Qin, Yue Chen, Qizhi Ma, and Pei Shu modified literature review. Wang YS contributed to the conception of the study.

\section{Acknowledgments}

This work was supported by the National Natural Science Foundation of China (Grant no. 81872489).

\section{References}

[1] L. B. Kennedy and A. K. S. Salama, "A review of cancer immunotherapy toxicity," CA: a Cancer Journal for Clinicians, vol. 70, no. 2, pp. 86-104, 2020.

[2] S. Zhang, Progress in Cancer Immunotherapy, Springer Netherlands, Dordrecht, Netherlands, 2016.

[3] J. Zhang and Z. Zhang, "The history and advances in cancer immunotherapy: understanding the characteristics of tumor-infiltrating immune cells and their therapeutic 
implications," Cellular \& Molecular Immunology, vol. 17, pp. 807-821, 2020.

[4] M. K. Chuk, J. T. Chang, M. R. Theoret et al., "FDA approval summary: accelerated approval of pembrolizumab for second-line treatment of metastatic melanoma," Clinical Cancer Research, vol. 19, 2017.

[5] D. E. Johnson, B. Burtness, C. R. Leemans, V. W. Y. Lui, J. E. Bauman, and J. R. Grandis, "Head and neck squamous cell carcinoma," Nature Reviews Disease Primers, vol. 6, no. 1, p. 92, 2020.

[6] G. Kwok, T. C. C. Yau, J. W. Chiu, E. Tse, and Y. L. Kwong, "Pembrolizumab (keytruda)," Human Vaccines \& Immunotherapeutics, vol. 12, no. 11, pp. 2777-2789, 2016.

[7] Y. Liu, L. Wu, R. Tong et al., "PD-1/PD-L1 inhibitors in cervical cancer," Frontiers in Pharmacology, vol. 10, p. 65, 2019.

[8] S. S. Joshi, S. B. Maron, and D. V. Catenacci, "Pembrolizumab for treatment of advanced gastric and gastroesophageal junction adenocarcinoma," Future Oncology, vol. 14, no. 5, pp. 417-430, 2018.

[9] J. Qu, M. Jiang, L. Wang et al., "Mechanism and potential predictive biomarkers of immune checkpoint inhibitors in NSCLC," Biomedicine \& Pharmacotherapy, vol. 127, Article ID 109996, 2020.

[10] K. Ganesh, Z. K. Stadler, A. Cercek et al., "Immunotherapy in colorectal cancer: rationale, challenges and potential," $\mathrm{Na}$ ture Reviews Gastroenterology \& Hepatology, vol. 16, no. 6, pp. 361-375, 2019.

[11] E. Zhang, J. Gu, and H. Xu, "Prospects for chimeric antigen receptor-modified T cell therapy for solid tumors," Molecular Cancer, vol. 17, no. 1, p. 7, 2018.

[12] 2017 First-Ever CAR T-cell Therapy Approved in U.S. Cancer Discov 7, Of1.

[13] M. L. Davila, I. Riviere, X. Wang et al., "Efficacy and toxicity management of 19-28z CAR T cell therapy in B cell acute lymphoblastic leukemia," Science Translational Medicine, vol. 6, Article ID 224ra25, 2014.

[14] G. Ding and H. Chen, "Adoptive transfer of T cells transduced with a chimeric antigen receptor to treat relapsed or refractory acute leukemia: efficacy and feasibility of immunotherapy approaches," Science China Life Sciences, vol. 59, no. 7, pp. 673-677, 2016.

[15] J. B. Stone and L. M. DeAngelis, "Cancer-treatment-induced neurotoxicity-focus on newer treatments," Nature Reviews Clinical Oncology, vol. 13, no. 2, pp. 92-105, 2016.

[16] U. By, M. J. Winkler, O. Manzke, H. Schulz, V. Diehl, and A. Engert, "Cytokine-release syndrome in patients with B-cell chronic lymphocytic leukemia and high lymphocyte counts after treatment with an anti-CD20 monoclonal antibody (rituximab, IDEC-C2B8)," Blood, vol. 94, pp. 22172224, 2016.

[17] G. Suntharalingam, R. P. Meghan, S. Ward et al., "Cytokine storm in a phase 1 trial of the anti-CD28 monoclonal antibody TGN1412," The New England Journal of Medicine, vol. 355, pp. 1018-1028, 2016.

[18] S. Li, Z. Yang, J. Shen, J. Shan, and C. Qian, "Adoptive therapy with CAR redirected T cells for hematological malignancies," Science China Life Sciences, vol. 59, no. 4, pp. 370-378, 2016.

[19] M. S. Topp, N. Gökbuget, A. S. Stein et al., "Safety and activity of blinatumomab for adult patients with relapsed or refractory B-precursor acute lymphoblastic leukaemia: a multicentre, single-arm, phase 2 study," The Lancet Oncology, vol. 16, no. 1, pp. 57-66, 2015.
[20] S. Cuzzubbo, F. Javeri, M. Tissier et al., "Neurological adverse events associated with immune checkpoint inhibitors: review of the literature," European Journal of Cancer, vol. 73, pp. 1-8, 2017.

[21] B. D. Santomasso, J. H. Park, D. Salloum et al., "Clinical and biological correlates of neurotoxicity associated with CAR T-cell therapy in patients with B-cell acute lymphoblastic leukemia," Cancer Discovery, vol. 8, no. 8, pp. 958-971, 2018.

[22] L. DeFrancesco, "CAR-T's forge ahead, despite Juno deaths," Nature Biotechnology, vol. 35, no. 1, pp. 6-7, 2017.

[23] S. S. Neelapu, S. Tummala, P. Kebriaei et al., "Chimeric antigen receptor T-cell therapy-assessment and management of toxicities," Nature Reviews Clinical Oncology, vol. 15, no. 1, pp. 47-62, 2018.

[24] A. Orcurto, A. Hottinger, B. Wolf et al., "Guillain-barré syndrome after adoptive cell therapy with tumorinfiltrating lymphocytes," Journal for Immunotherapy of Cancer, vol. 8, no. 2, Article ID e001155, 2020.

[25] S. Wilgenhof and B. Neyns, "Anti-CTLA-4 antibody-induced guillain-barré syndrome in a melanoma patient," Annals of Oncology, vol. 22, no. 4, pp. 991-993, 2011.

[26] B. Liao, S. Shroff, C. Kamiya-Matsuoka, and S. Tummala, "Atypical neurological complications of ipilimumab therapy in patients with metastatic melanoma," Neuro-Oncology, vol. 16, no. 4, pp. 589-593, 2014.

[27] R. Tanaka, H. Maruyama, Y. Tomidokoro et al., "Nivolumabinduced chronic inflammatory demyelinating polyradiculoneuropathy mimicking rapid-onset guillain-barré syndrome: a case report," Japanese Journal of Clinical Oncology, vol. 46, no. 9, pp. 875-878, 2016.

[28] H. B. Wang, F. D. Shi, H. Li, B. J. Chambers, H. Link, and H. G. Ljunggren, "Anti-CTLA-4 antibody treatment triggers determinant spreading and enhances murine myasthenia gravis," The Journal of Immunology, vol. 166, no. 10, pp. 6430-6436, 2001.

[29] K. H. V. Lau, A. Kumar, I. H. Yang, and R. J. Nowak, "Exacerbation of myasthenia gravis in a patient with melanoma treated with pembrolizumab," Muscle \& Nerve, vol. 54, no. 1, pp. 157-161, 2016.

[30] Common Terminology Criteria for Adverse Events (CTCAE) Version 5. Published: November 27. US Department of Health and Human Services, National Institutes of Health, National Cancer Institute, Bethesda, MD, USA, 2017.

[31] S. J. Antonia, A. Villegas, D. Daniel et al., "Durvalumab after chemoradiotherapy in stage III non-small-cell lung cancer," New England Journal of Medicine, vol. 377, no. 20, pp. 1919-1929, 2017.

[32] A. M. M. Eggermont, V. Chiarion-Sileni, J. J. Grob et al., "Adjuvant ipilimumab versus placebo after complete resection of high-risk stage III melanoma (EORTC 18071): a randomised, double-blind, phase 3 trial," The Lancet Oncology, vol. 16, no. 5, pp. 522-530, 2015.

[33] A. Argiris, T. M. Feinstein, L. Wang et al., "Phase I and pharmacokinetic study of dasatinib and cetuximab in patients with advanced solid malignancies," Investigational New Drugs, vol. 30, no. 4, pp. 1575-1584, 2012.

[34] M. E. Goebeler, S. Knop, A. Viardot et al., "Bispecific T-cell engager (BiTE) antibody construct blinatumomab for the treatment of patients with relapsed/refractory non-hodgkin lymphoma: final results from a phase I study," Journal of Clinical Oncology, vol. 34, no. 10, pp. 1104-1111, 2016.

[35] R. Wierzbicki, D. J. Jonker, M. J. Moore et al., "A phase II, multicenter study of cetuximab monotherapy in patients with refractory, metastatic colorectal carcinoma with absent 
epidermal growth factor receptor immunostaining," Investigational New Drugs, vol. 29, no. 1, pp. 167-174, 2011.

[36] S. Chakraborty, C. G. Filippi, J. K. Burkhardt et al., "Durability of single dose intra-arterial bevacizumab after blood/ brain barrier disruption for recurrent glioblastoma," Journal of Experimental Therapeutics \& Oncology, vol. 11, pp. 261267, 2016.

[37] M. J. Matasar, M. Capra, M. Özcan et al., "Copanlisib plus rituximab versus placebo plus rituximab in patients with relapsed indolent non-hodgkin lymphoma (CHRONOS-3): a double-blind, randomised, placebo-controlled, phase 3 trial," The Lancet Oncology, vol. 22, no. 5, pp. 678-689, 2021.

[38] O. Hamid, C. Robert, A. Daud et al., "Safety and tumor responses with lambrolizumab (anti-PD-1) in melanoma," New England Journal of Medicine, vol. 369, no. 2, pp. 134144, 2013.

[39] R. I. Davila, X. Wang, S. Bartido et al., "Efficacy and toxicity management of $19-28 z$ CAR T cell therapy in B cell acute lymphoblastic leukemia," New England Journal of Medicine, vol. 374, p. 998, 2016.

[40] D. M. Barrett, D. T. Teachey, and S. A. Grupp, "Toxicity management for patients receiving novel T-cell engaging therapies," Current Opinion in Pediatrics, vol. 26, no. 1, pp. 43-49, 2014.

[41] J. M. Josep-Maria Ribera, A. Ferrer, J. Ribera, and E. Genesca, "Profile of blinatumomab and its potential in the treatment of relapsed/refractory acute lymphoblastic leukemia," OncoTargets and Therapy, vol. 8, pp. 1567-1574, 2015.

[42] J. Gust, K. A. Hay, L. A. Hanafi et al., "Endothelial activation and blood-brain barrier disruption in neurotoxicity after adoptive immunotherapy with CD19 CAR-T Cells," Cancer Discovery, vol. 7, no. 12, pp. 1404-1419, 2017.

[43] A. M. Evens, M. R. Smith, I. S. Lossos et al., "Frontline bortezomib and rituximab for the treatment of newly diagnosed high tumour burden indolent non-hodgkin lymphoma: a multicentre phase II study," British Journal of Haematology, vol. 166, no. 4, pp. 514-520, 2014.

[44] C. P. Mavragani, P. G. Vlachoyiannopoulos, N. Kosmas, I. Boletis, A. G. Tzioufas, and M. Voulgarelis, "A case of reversible posterior leucoencephalopathy syndrome after rituximab infusion," Rheumatology, vol. 43, no. 11, pp. 1450-1451, 2004.

[45] A. Siddiqi, "Rituximab as a possible cause of posterior reversible encephalopathy syndrome," Australasian Medical Journal, vol. 4, no. 9, pp. 513-515, 2011.

[46] R. Dada, J. Zekri, B. Ramal, and K. Ahmad, "Acute jugular vein thrombosis during rituximab administration: review of the literature," Journal of Oncology Pharmacy Practice, vol. 22, no. 1, pp. 165-169, 2016.

[47] A. Sánchez-Carteyron, R. Alarcia, J. R. Ara, and J. Martín, "Posterior reversible encephalopathy syndrome after rituximab infusion in neuromyelitis optica," Neurology, vol. 74, no. 18 , pp. $1471-1473,2010$.

[48] F. Ceppi, S. Weitzman, W. Woessmann et al., "Safety and efficacy of intrathecal rituximab in children with B cell lymphoid $\mathrm{CD} 20+$ malignancies: an international retrospective study," American Journal of Hematology, vol. 91, no. 5, pp. 486-491, 2016.

[49] R. C. S. Seet and A. A. Rabinstein, "Clinical features and outcomes of posterior reversible encephalopathy syndrome following bevacizumab treatment," Qjm, vol. 105, no. 1, pp. 69-75, 2012.

[50] M. Maur, C. Tomasello, A. Frassoldati, M. V. Dieci, E. Barbieri, and P. Conte, "Posterior reversible encephalopathy syndrome during ipilimumab therapy for malignant melanoma," Journal of Clinical Oncology, vol. 30, no. 6, pp. e76-e78, 2012.

[51] M. I. Stefanou, I. Gepfner-Tuma, C. Brendle et al., "Posterior reversible encephalopathy syndrome in a melanoma patient with dabrafenib and trametinib treatment following immunotherapy," JDDG: Journal der Deutschen Dermatologischen Gesellschaft, vol. 18, no. 2, pp. 136-139, 2020

[52] M. S. Topp, P. Kufer, N. Gökbuget et al., "Targeted therapy with the T-cell-engaging antibody blinatumomab of chemotherapy-refractory minimal residual disease in B-lineage acute lymphoblastic leukemia patients results in high response rate and prolonged leukemia-free survival," Journal of Clinical Oncology, vol. 29, no. 18, pp. 2493-2498, 2011.

[53] R. Bargou, E. Leo, G. Zugmaier et al., "Tumor regression in cancer patients by very low doses of a T cell-engaging antibody," Science, vol. 321, no. 5891, pp. 974-977, 2008.

[54] C. Turtle, S. Riddell, and D. Maloney, "CD19-Targeted chimeric antigen receptor-modified T-cell immunotherapy for B-cell malignancies," Clinical Pharmacology \& Therapeutics, vol. 100, no. 3, pp. 252-258, 2016.

[55] R. M. Conry, J. C. Sullivan, and L. B. Nabors 3rd, "Ipilimumab-induced encephalopathy with a reversible splenial lesion," Cancer Immunology Research, vol. 3, no. 6, pp. 598-601, 2015.

[56] K. C. Kähler, J. C. Hassel, L. Heinzerling et al., "Management of side effects of immune checkpoint blockade by antiCTLA-4 and anti-PD-1 antibodies in metastatic melanoma," JDDG: Journal der Deutschen Dermatologischen Gesellschaft, vol. 14, no. 7, pp. 662-681, 2016.

[57] M. Hamid, A. Ghani, I. Micaily, U. Sarwar, B. Lashari, and F. Malik, "Posterior reversible encephalopathy syndrome (PRES) after bevacizumab therapy for metastatic colorectal cancer," Journal of Community Hospital Internal Medicine Perspectives, vol. 8, no. 3, pp. 130-133, 2018.

[58] L. W. Buie, J. J. Pecoraro, T. Z. Horvat, and R. J. Daley, "Blinatumomab," Annals of Pharmacotherapy, vol. 49, no. 9, pp. 1057-1067, 2015.

[59] C. J. Turtle, L. A. Hanafi, C. Berger et al., "CD19 CAR-T cells of defined CD4+:CD8+ composition in adult B cell ALL patients," Journal of Clinical Investigation, vol. 126, no. 6 , pp. 2123-2138, 2016.

[60] J. T. Cameron, H. Laila-Aicha, C. Berger et al., "Immunotherapy of non-hodgkin's lymphoma with a defined ratio of $\mathrm{CD} 8+$ and CD4+ CD19-specific chimeric antigen receptor-modified T cells," Cancer, vol. 8, 2016.

[61] E. O. Major, "Progressive multifocal leukoencephalopathy in patients on immunomodulatory therapies," Annual Review of Medicine, vol. 61, no. 1, pp. 35-47, 2010.

[62] K. R. Carson, A. M. Evens, E. A. Richey et al., "Progressive multifocal leukoencephalopathy after rituximab therapy in HIV-negative patients: a report of 57 cases from the research on adverse drug events and reports project," Blood, vol. 113, no. 20 , pp. $4834-4840,2009$

[63] K. R. Carson, S. D. Newsome, E. J. Kim et al., "Progressive multifocal leukoencephalopathy associated with brentuximab vedotin therapy: a report of 5 cases from the southern network on adverse reactions (SONAR) project," Cancer, vol. 120, no. 16, pp. 2464-2471, 2014.

[64] M. Martinot, G. Ahle, I. Petrosyan et al., "Progressive multifocal leukoencephalopathy after treatment with nivolumab," Emerging Infectious Diseases, vol. 24, no. 8, pp. 1594-1596, 2018. 
[65] S. Appel, Z. Nitsan, A. Gelfand et al., "Progressive multifocal leukoencephalopathy in a patient with chronic lymphocytic leukemia following immunosuppressive treatment," Neurology \& Clinical Neuroscience, vol. 44, 2016.

[66] K. Sdrimas, M. Diaz-Paez, J. F. Camargo, and L. J. Lekakis, "Progressive multifocal leukoencephalopathy after CAR T therapy," International Journal of Hematology, vol. 112, no. 1, pp. 118-121, 2020.

[67] N. L. Bartlett, R. Chen, M. A. Fanale et al., "Retreatment with brentuximab vedotin in patients with CD30-positive hematologic malignancies," Journal of Hematology \& Oncology, vol. 7, no. 1, p. 24, 2014.

[68] A. Younes, N. L. Bartlett, J. P. Leonard et al., "Brentuximab vedotin (SGN-35) for relapsed CD30-positive lymphomas," New England Journal of Medicine, vol. 363, no. 19, pp. 1812-1821, 2010.

[69] J. Brahmer, K. L. Reckamp, P. Baas et al., "Nivolumab versus docetaxel in advanced squamous-cell non-small-cell lung cancer," New England Journal of Medicine, vol. 373, no. 2, pp. 123-135, 2015.

[70] C. Robert, A. Ribas, J. D. Wolchok et al., "Anti-programmeddeath-receptor-1 treatment with pembrolizumab in ipilimumab-refractory advanced melanoma: a randomised dosecomparison cohort of a phase 1 trial," The Lancet, vol. 384, no. 9948, pp. 1109-1117, 2014.

[71] M. A. Fanale, A. Forero-Torres, J. D. Rosenblatt et al., "A phase I weekly dosing study of brentuximab vedotin in patients with relapsed/refractory CD30-positive hematologic malignancies," Clinical Cancer Research, vol. 18, no. 1, pp. 248-255, 2012.

[72] V. Tsang, "Brentuximab vedotin in hodgkin lymphoma and anaplastic large cell lymphoma," Journal of the Advanced Practitioner in Oncology, vol. 3, pp. 184-190, 2012.

[73] Y. T. Yang, C. J. Tai, C. Chen et al., "Highly diverse efficacy of salvage treatment regimens for relapsed or refractory peripheral T-Cell lymphoma: a systematic review," PLoS One, vol. 11, no. 10, Article ID e0161811, 2016.

[74] A. Forero-Torres, B. Holkova, J. Goldschmidt et al., "Phase 2 study of frontline brentuximab vedotin monotherapy in hodgkin lymphoma patients aged 60 years and older," Blood, vol. 126, no. 26, pp. 2798-2804, 2015.

[75] M. Duvic, M. T. Tetzlaff, P. Gangar, A. L. Clos, D. Sui, and R. Talpur, "Results of a Phase II trial of brentuximab vedotin for CD30+ cutaneous T-cell lymphoma and lymphomatoid papulosis," Journal of Clinical Oncology, vol. 33, no. 32, pp. 3759-3765, 2015.

[76] Q. M. Yang, J. Y. Hong, Y. H. Ko et al., "Brentuximab vedotin for relapsed or refractory $\mathrm{CD} 30+$ hodgkin lymphoma: a multicenter analysis from Asia," Onco Targets Ther, vol. 7, pp. 1717-1722, 2014.

[77] D. Leveque, "Subcutaneous administration of anticancer agents," Anticancer Research, vol. 34, pp. 1579-1586, 2014.

[78] I. Thaipisuttikul, P. Chapman, and E. K. Avila, "Peripheral neuropathy associated with ipilimumab," Journal of Immunotherapy, vol. 38, no. 2, pp. 77-79, 2015.

[79] M. Hardwick, L. Nolan, J. A. R. Nicoll et al., "CD8 T-cellmediated cerebellitis directed against purkinje cell antigen after ipilimumab for small cell lung cancer," Neuropathology Applied Neurobiology, 2021.

[80] T. Naito, M. Osaki, M. Ubano, M. Kanzaki, and Y. Uesaka, "Acute cerebellitis after administration of nivolumab and ipilimumab for small cell lung cancer," Neurological Sciences, vol. 39, no. 10, pp. 1791-1793, 2018.
[81] A. Goldhirsch, R. D. Gelber, M. J. Piccart-Gebhart et al., “2 years versus 1 year of adjuvant trastuzumab for HER2positive breast cancer (HERA): an open-label, randomised controlled trial," The Lancet, vol. 382, no. 9897, pp. 1021-1028, 2013.

[82] R. S. Magge and L. M. DeAngelis, "The double-edged sword: neurotoxicity of chemotherapy," Blood Reviews, vol. 29, no. 2, pp. 93-100, 2015.

[83] H. Safa, D. H. Johnson, V. A. Trinh et al., "Immune checkpoint inhibitor related myasthenia gravis: single center experience and systematic review of the literature," Journal for Immunotherapy of Cancer, vol. 7, no. 1, p. 319, 2019.

[84] J. Larkin, B. Chmielowski, C. D. Lao et al., "Neurologic serious adverse events associated with nivolumab plus ipilimumab or nivolumab alone in advanced melanoma, including a case series of encephalitis," The Oncologist, vol. 22, no. 6, pp. 709-718, 2017.

[85] T. Shirai, T. Sano, F. Kamijo et al., "Acetylcholine receptor binding antibody-associated myasthenia gravis and rhabdomyolysis induced by nivolumab in a patient with melanoma," Japanese Journal of Clinical Oncology, vol. 46, no. 1, pp. 86-88, 2016.

[86] M. Algaeed, L. Mukharesh, M. Heinzelmann, and H. J. Kaminski, "Pearls \& Oy-sters: pembrolizumab-induced myasthenia gravis," Neurology, vol. 91, no. 14, pp. e1365-e1367, 2018.

[87] J. C. Kao, A. Brickshawana, and T. Liewluck, "Neuromuscular complications of programmed cell death-1 (PD-1) inhibitors," Current Neurology and Neuroscience Reports, vol. 18, no. 10, p. 63, 2018.

[88] D. B. Johnson, V. Saranga-Perry, P. J. M. Lavin et al., "Myasthenia gravis induced by ipilimumab in patients with metastatic melanoma," Journal of Clinical Oncology, vol. 33, no. 33, pp. e122-e124, 2015.

[89] A. I. Loochtan, M. S. Nickolich, and L. D. Hobson-Webb, "Myasthenia gravis associated with ipilimumab and nivolumab in the treatment of small cell lung cancer," Muscle \& Nerve, vol. 52, no. 2, pp. 307-308, 2015.

[90] Y. Tu, X. Gong, G. Zeng, W. Zhuo, Z. Li, and X. Yu, "Differences in thyroid function and autoantibodies in the development of guillain-barré syndrome vs. chronic inflammatory demyelinating polyradiculoneuropathy," Frontiers in Neurology, vol. 11, 2020.

[91] D. Makarious, K. Horwood, and J. I. G. Coward, "Myasthenia gravis: an emerging toxicity of immune checkpoint inhibitors," European Journal of Cancer, vol. 82, pp. 128-136, 2017.

[92] J. Joseph, M. J. Nathenson, V. A. Trinh et al., "Guillain-barre syndrome observed with adoptive transfer of lymphocytes genetically engineered with an NY-ESO-1 reactive T-cell receptor," Journal for Immunotherapy of Cancer, vol. 7, no. 1, p. 296, 2019.

[93] C. Maritaz, C. Metz, N. Baba-Hamed, M. Jardin-Szucs, and G. Deplanque, "Cetuximab-induced aseptic meningitis: case report and review of a rare adverse event," BMC Cancer, vol. 16, no. 1, p. 384, 2016.

[94] J. C. Kao, B. Liao, S. N. Markovic et al., "Neurological complications associated with anti-programmed death 1 (PD-1) antibodies," JAMA Neurology, vol. 74, no. 10, pp. 1216-1222, 2017.

[95] M. K. Stein, B. B. Summers, C. A. Wong, H. L. Box, and K. O. Cleveland, "Meningoencephalitis following ipilimumab administration in metastatic melanoma," The American Journal of the Medical Sciences, vol. 350, no. 6, pp. 512-513, 2015. 
[96] J. A. Thompson, B. J. Schneider, J. Brahmer et al., "Management of Immunotherapy-related toxicities, version 1.2019 , NCCN clinical practice guidelines in oncology," Journal of the National Comprehensive Cancer Network, vol. 17, no. 3, pp. 255-289, 2019.

[97] A. Ribas, R. Kefford, M. A. Marshall et al., "Phase III randomized clinical trial comparing tremelimumab with standard-of-care chemotherapy in patients with advanced melanoma," Journal of Clinical Oncology, vol. 31, no. 5, pp. 616-622, 2013.

[98] M. Aglietta, C. Barone, M. B. Sawyer et al., "A phase I dose escalation trial of tremelimumab (CP-675,206) in combination with gemcitabine in chemotherapy-naive patients with metastatic pancreatic cancer," Annals of Oncology, vol. 25, no. 9, pp. 1750-1755, 2014.

[99] A. M. Joshua, J. G. Monzon, C. Mihalcioiu, D. Hogg, M. Smylie, and T. Cheng, "A phase 2 study of tremelimumab in patients with advanced uveal melanoma," Melanoma Research, vol. 25, no. 4, pp. 342-347, 2015.

[100] D. G. McNeel, H. A. Smith, J. C. Eickhoff et al., "Phase I trial of tremelimumab in combination with short-term androgen deprivation in patients with PSA-recurrent prostate cancer," Cancer Immunology, Immunotherapy, vol. 61, no. 7, pp. 1137-1147, 2012.

[101] R. T. Maziarz, S. J. Schuster, V. V. Romanov et al., "Grading of neurological toxicity in patients treated with tisagenlecleucel in the JULIET trial," Blood Advances, vol. 4, no. 7, pp. 1440-1447, 2020.

[102] D. T. Teachey, S. R. Rheingold, S. L. Maude et al., "Cytokine release syndrome after blinatumomab treatment related to abnormal macrophage activation and ameliorated with cytokine-directed therapy," Blood, vol. 121, no. 26, pp. 5154-5157, 2013.

[103] J. N. Brudno and J. N. Kochenderfer, "Toxicities of chimeric antigen receptor $\mathrm{T}$ cells: recognition and management," Blood, vol. 127, no. 26, pp. 3321-3330, 2016.

[104] B. L. Marini, Y. Sun, P. W. Burke, and A. J. Perissinotti, "Successful reintroduction of blinatumomab in a patient with relapsed/refractory acute lymphoblastic leukemia following grade 4 cytokine release syndrome," Journal of Oncology Pharmacy Practice, vol. 24, 2016.

[105] M. Ruella, S. S. Kenderian, O. Shestova et al., "Kinase inhibitor ibrutinib to prevent cytokine-release syndrome after anti-CD19 chimeric antigen receptor $\mathrm{T}$ cells for B-cell neoplasms," Leukemia, vol. 31, 2017.

[106] S. J. Nagle, A. L. Garfall, and E. A. Stadtmauer, "The promise of chimeric antigen receptor engineered $\mathrm{T}$ cells in the treatment of hematologic malignancies," The Cancer Journal, vol. 22, no. 1, pp. 27-33, 2016.

[107] R. Nair, S. Gheith, and N. Lamparella, "Rituximab-induced splenic rupture and cytokine release," American Journal of Case Reports, vol. 17, pp. 165-169, 2016.

[108] J. N. Kochenderfer, M. E. Dudley, S. A. Feldman et al., "B-cell depletion and remissions of malignancy along with cytokineassociated toxicity in a clinical trial of anti-CD19 chimericantigen-receptor-transduced T cells," Blood, vol. 119, no. 12, pp. 2709-2720, 2012.

[109] M. Norelli, B. Camisa, G. Barbiera et al., "Monocyte-derived IL- 1 and IL- 6 are differentially required for cytokine-release syndrome and neurotoxicity due to CAR T cells," Nature Medicine, vol. 24, no. 6, pp. 739-748, 2018.

[110] K. Oishi, M. Nakao, S. Maeda et al., "A case of aseptic meningitis without neck rigidity occurring in a metastatic melanoma patient treated with ipilimumab," European Journal of Dermatology, vol. 27, no. 2, pp. 193-194, 2017.

[111] D. Prasanna, T. Elrafei, E. Shum, and M. Strakhan, "More than a headache: a case of cetuximab-induced aseptic meningitis," BMJ Case Reports, vol. 2015, 2015.

[112] J. A. Blansfield, K. E. Beck, K. Tran et al., "Cytotoxic T-lymphocyte-associated antigen-4 blockage can induce autoimmune hypophysitis in patients with metastatic melanoma and renal cancer," Journal of Immunotherapy, vol. 28, no. 6, pp. 593-598, 2005.

[113] W. G. Mayhan, "Cellular mechanisms by which tumor necrosis factor- $\alpha$ produces disruption of the blood-brain barrier," Brain Research, vol. 927, no. 2, pp. 144-152, 2002.

[114] L. Zimmer, S. M. Goldinger, L. Hofmann et al., "Neurological, respiratory, musculoskeletal, cardiac and ocular sideeffects of anti-PD-1 therapy," European Journal of Cancer, vol. 60 , pp. $210-225,2016$.

[115] J. J. Mandel, A. Olar, K. D. Aldape, and I. W. TremontLukats, "Lambrolizumab induced central nervous system (CNS) toxicity," Journal of the Neurological Sciences, vol. 344, no. 1-2, pp. 229-231, 2014.

[116] C. Romani, R. Murru, F. Adamo et al., "Sensorimotor peripheral neuropathy in an elderly AML patient in complete remission while receiving gemtuzumab ozogamicin as maintenance therapy," Annals of Hematology, vol. 85, no. 6, pp. 411-412, 2006.

[117] A. Nellan and D. W. Lee, "Paving the road ahead for CD19 CAR T-cell therapy," Current Opinion in Hematology, vol. 22, no. 6, pp. 516-520, 2015.

[118] N. Rollins, N. Winick, R. Bash, and T. Booth, "Acute methotrexate neurotoxicity: findings on diffusion-weighted imaging and correlation with clinical outcome," AJNR. American Journal of Neuroradiology, vol. 25, pp. 1688-1695, 2004.

[119] N. Letarte, L. R. Bressler, and J. L. Villano, "Bevacizumab and central nervous system (CNS) hemorrhage," Cancer Chemotherapy and Pharmacology, vol. 71, no. 6, pp. 1561-1565, 2013.

[120] F. Elice, F. Rodeghiero, A. Falanga, and F. R. Rickles, "Thrombosis associated with angiogenesis inhibitors," Best Practice \& Research Clinical Haematology, vol. 22, no. 1, pp. 115-128, 2009.

[121] F. S. Hodi, D. Lawrence, C. Lezcano et al., "Bevacizumab plus ipilimumab in patients with metastatic melanoma," Cancer Immunology Research, vol. 2, no. 7, pp. 632-642, 2014

[122] J. V. Pluvinage, M. S. Haney, B. A. H. Smith et al., "CD22 blockade restores homeostatic microglial phagocytosis in ageing brains," Nature, vol. 568, no. 7751, pp. 187-192, 2019.

[123] H. Trottestam, A. Horne, M. Aricò et al., "Chemoimmunotherapy for hemophagocytic lymphohistiocytosis: long-term results of the HLH-94 treatment protocol," Blood, vol. 118, no. 17, pp. 4577-4584, 2011.

[124] D. J. Byun, J. D. Wolchok, L. M. Rosenberg, and M. Girotra, "Cancer immunotherapy-immune checkpoint blockade and associated endocrinopathies," Nature Reviews Endocrinology, vol. 13, 2017.

[125] A. K. Persson, J. G. J. Hoeijmakers, M. Estacion, J. A. Black, and S. G. Waxman, "Sodium channels, mitochondria, and axonal degeneration in peripheral neuropathy," Trends in Molecular Medicine, vol. 22, no. 5, pp. 377-390, 2016.

[126] C. J. Voskens, S. M. Goldinger, C. Loquai et al., "The price of tumor control: an analysis of rare side effects of anti-CTLA-4 therapy in metastatic melanoma from the ipilimumab network," PLoS One, vol. 8, no. 1, Article ID e53745, 2013. 
[127] T. M. Feinstein, M. K. Gibson, and A. Argiris, "Cetuximabinduced aseptic meningitis," Annals of Oncology, vol. 20, no. 9, pp. 1609-1610, 2009.

[128] F. S. Hodi, D. A. Oble, J. Drappatz et al., "CTLA-4 blockade with ipilimumab induces significant clinical benefit in a female with melanoma metastases to the CNS," Nature Clinical Practice Oncology, vol. 5, no. 9, pp. 557-561, 2008.

[129] I. Bot, C. U. Blank, W. Boogerd, and D. Brandsma, "Neurological immune-related adverse events of ipilimumab," Practical Neurology, vol. 13, no. 4, pp. 278-280, 2013.

[130] L. A. Fecher, S. S. Agarwala, F. S. Hodi, and J. S. Weber, "Ipilimumab and its toxicities: a multidisciplinary approach," The Oncologist, vol. 18, no. 6, pp. 733-743, 2013.

[131] P. Schlegel, P. Lang, G. Zugmaier et al., "Pediatric posttransplant relapsed/refractory B-precursor acute lymphoblastic leukemia shows durable remission by therapy with the T-cell engaging bispecific antibody blinatumomab," Haematologica, vol. 99, no. 7, pp. 1212-1219, 2014.

[132] T. K. Eigentler, J. C. Hassel, C. Berking et al., "Diagnosis, monitoring and management of immune-related adverse drug reactions of anti-PD-1 antibody therapy," Cancer Treatment Reviews, vol. 45, pp. 7-18, 2016.

[133] F. Torino, S. M. Corsello, and R. Salvatori, "Endocrinological side-effects of immune checkpoint inhibitors," Current Opinion in Oncology, vol. 28, no. 4, pp. 278-287, 2016.

[134] Y. Okano, T. Satoh, K. Horiguchi et al., "Nivolumab-induced hypophysitis in a patient with advanced malignant melanoma," Endocrine Journal, vol. 63, no. 10, pp. 905-912, 2016.

[135] M. Ishikawa and K. Oashi, "Case of hypophysitis caused by nivolumab," The Journal of Dermatology, vol. 44, no. 1, pp. 109-110, 2017.

[136] K. D. Denicoff, T. M. Durkin, M. T. Lotze et al., "The neuroendocrine effects of interleukin-2 treatment," The Journal of Clinical Endocrinology \& Metabolism, vol. 69, no. 2, pp. 402-410, 1989.

[137] K. H. Begna, R. A. Mesa, A. Pardanani et al., "A phase-2 trial of low-dose pomalidomide in myelofibrosis," Leukemia, vol. 25, no. 2, pp. 301-304, 2011.

[138] T. N. Kreisl, "Neurologic complications of antitumor antibody therapies," Current Neurology and Neuroscience Reports, vol. 8, no. 3, pp. 259-263, 2008.

[139] J. A. Dubovsky, K. A. Beckwith, G. Natarajan et al., "Ibrutinib is an irreversible molecular inhibitor of ITK driving a Th1selective pressure in T lymphocytes," Blood, vol. 122, no. 15, pp. 2539-2549, 2013.

[140] E. Huarte, R. S. O’Connor, M. T. Peel et al., "Itacitinib (INCB039110), a JAK1 inhibitor, reduces cytokines associated with cytokine release syndrome induced by CAR T-cell therapy," Clinical Cancer Research, vol. 26, no. 23, pp. 6299-6309, 2020. 